J Ästhet Chir 2010 · 3:174

DOI 10.1007/s12631-010-0100-5

(c) Springer-Verlag 2010

\author{
H.-G. Bull \\ St. Josefshospital Uerdingen, Krefeld
}

\title{
Interdisziplinarität wird groß geschrieben
}

Sehr geehrte Kolleginnen und Kollegen,

das Journal für Ästhetische Chirurgie hat in dieser Ausgabe das Schwerpunktthema Bauchdeckenplastik und Fettabsaugung. Dieses Thema ist ein gutes Beispiel für die interdisziplinäre Zusammenarbeit, wie sie in der Gesellschaft für Ästhetische Chirurgie - mit hoher Verantwortung den Patienten gegenüber - gepflegt wird.

Wie Sie anhand der Themenzusammenstellung (s. Box auf dieser Seite) erkennen können, spiegelt sich diese Interdisziplinarität auch in den Leitthemen der letzten 2 Jahre wider. Dank eines hervorragend besetzten Herausgeberboards mit Experten aus den verschiedenen Fachdisziplinen, so der Plastischen Chirurgie, Dermatologie, Gynäkologie, HNO-Heilkunde oder der MKG-Chirurgie, war bzw. ist es möglich, das große Spektrum der ästhetischen Chirurgie kritisch und auf neuestem wissenschaftlichen Stand abzuhandeln und zu diskutieren.

Im Namen der Gesellschaft für Ästhetische Chirurgie Deutschland e.V. danke ich den Autoren dieses sowie der vorangegangenen Hefte des Journal für Ästhetische Chirurgie sehr herzlich für Ihre Mitarbeit an unserem Journal. Selbst- verständlich sind auch Sie herzlich eingeladen, das Journal für Ästhetische Chirurgie mit einem Beitrag zu bereichern. Alle wichtigen Details sowie Autorenleitfäden und Musterbeiträge finden Sie online unter www.JournalfuerAesthetischeChirurgie.de/Autoren.

Ich wünsche Ihnen viel Freude bei der Lektüre dieser Ausgabe.

Ihr

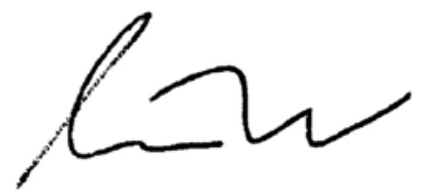

Prof. Dr. Dr. H.-G. Bull Schriftleiter Journal für Ästhetische Chirurgie

\section{Korrespondenzadresse}

Prof. Dr. Dr. H.-G. Bull

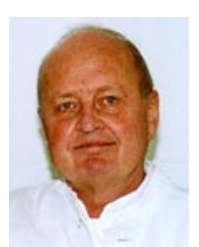

St. Josefshospital Uerdingen Kurfürstenstr. 69, 47829 Krefeld bull.mkg@stjosef.de 